\title{
Risk factors for knee replacement due to primary osteoarthritis, a population based, prospective cohort study of 315,495 individuals
}

Hilde Apold ${ }^{1 *}$, Haakon E Meyer ${ }^{2,3}$, Lars Nordsletten ${ }^{4,5}$, Ove Furnes ${ }^{6,7,8}$, Valborg Baste ${ }^{6}$ and Gunnar B Flugsrud ${ }^{4}$

\begin{abstract}
Background: Osteoarthritis $(\mathrm{OA})$ of the knee is a common and disabling condition. We wanted to investigate the modifiable risk factors Body Mass Index (BMI) and physical activity, using knee replacement (KR) as a marker for severely symptomatic disease, focusing on the interaction between these risk factors.

Methods: 315,495 participants (mean age 43.0 years) from national health screenings were followed prospectively with respect to KR identified by linkage to the Norwegian Arthroplasty Register. Data were analysed by Cox proportional hazard regression.

Results: During 12 years of follow up 1,323 individuals received KR for primary OA. There was a dose-response relationship between BMI and heavy labour, and later KR. Comparing the highest versus the lowest quarter of BMI, the relative risk was 6.2 (95\% Cl: 4.2-9.0) in men and 11.1 (95\% Cl: 7.8-15.6) in women. Men reporting intensive physical activity at work had a relative risk of 2.4 (95\% Cl: 1.8-3.2) versus men reporting sedentary activity at work, the corresponding figure in women being 2.3 (95\% Cl: 1.7-3.2). The effect of BMl and physical activity at work was additive. The heaviest men with the most strenuous work had a RR of 11.7 ( $95 \% \mathrm{Cl}$ : 5.9-23.1) compared to the ones with the lowest BMI and most sedentary work. For women the corresponding RR was 15.8 (95\% Cl: 8.2-30.3). There was no association between physical activity during leisure and KR.

Conclusion: We found that a high BMI and intensive physical activity at work both contribute strongly to the risk of having a KR. As the two risk factors seem to act independently, people with strenuous physical work with a high $\mathrm{BMI}$ are at particularly high risk for severely disabling $\mathrm{OA}$ of the knee, and should be targeted with effective preventive measures.
\end{abstract}

Keywords: Osteoarthritis, Obesity, Knee joint replacement, Body mass index, Risk factor, Epidemiology

\section{Background}

The etiology of osteoarthritis (OA) of the knee is multifactorial, and several studies and also meta-analyses have identified risk factors for the disease. Family history [1], age [2,3], ethnicity [4] and gender [5] are risk factors that make the joint more susceptible to the development of OA. Injury [6,7], physical activity [6,8-17], malalignment $[18,19]$, smoking [6,20-26], and overweight $[8,20,25,27-29]$ have also been well studied. BMI is one of the best documented risk factors for knee OA [8,20,25,27-29]. In a

\footnotetext{
* Correspondence: Hilde.apold@medisin.uio.no

'Orthopaedic department, Telemark Hospital, Skien, Norway

Full list of author information is available at the end of the article
}

meta-analysis those who were overweight or obese had 2.96-times higher risk for knee OA than those with a normal weight (95\% CI: 2.56-3.43) [25]. There is evidence that even weight within what is defined as normal according to the international classification of body-weight, do increase the risk of knee OA [30,31].

There has been reported conflicting evidence on the effect of smoking on OA. Two studies defining knee OA by $\mathrm{x}$-ray changes or symptoms reported lower risk associated with smoking $[6,20]$, and a recent study using joint replacement as a marker of OA found an inverse doseresponse association between duration of smoking and joint replacement [32]. Other studies have found no association $[22,23]$, and two meta-analyses have pointed out

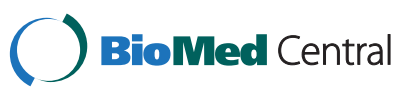


that the protective effect of smoking on incident OA was only apparent when pooling the results of case-control studies and cohort studies [24,25]. When restricting analyses to cohort studies the effect was no longer apparent. Hui et al. concluded that the negative association could be due to selection bias [24]. They noted that the use of controls recruited from hospitals is likely to include a higher proportion of smokers than the non-hospitalized population, and this could lead to a false negative association between smoking and OA. They also found that since smokers are normally thinner than non-smokers adjusting for BMI diluted the reported negative association between smoking and OA. In a more recent meta-analysis by the same group they investigated the effect of smoking on the progression of $\mathrm{OA}$ and made similar conclusions of no evidence of a protective effect of smoking on the progression of OA [26].

Occupational activity has been investigated by different occupations and by degree of work load. It has been reported a limited protective effect of sitting over 2 hours a day, and an increased risk in those kneeling and squatting excessively at work, and some occupations like farmers, construction workers, firefighters and floor-layers have been reported to have an increased risk of knee OA [6,8-11]. Meta-analyses have found evidence for a relationship between occupational activities involving kneeling, heavy lifting and knee $\mathrm{OA}$, and that certain occupations like floor layers, and miners have an increased risk of knee OA [33,34].

Studies of physical activity at leisure and knee OA have shown some conflicting results [12-17]. Some studies have reported a protective effect on the joint [15], others no effect $[13,17,35,36]$, and even others a detrimental effect on the knee joint $[12,14,20]$. A systematic review article from 2006 concluded that joint trauma was a greater risk factor than the sport itself and that the risk of OA was associated with the duration and intensity of the exposure [16]. Another systematic review from 2011, Urquhart et al. found that different measures of OA responded differently to physical activity. Physical activity was associated with an increase of osteophytes, but not with joint space narrowing, and also with some evidence of an increased cartilage volume measured with MRI. They suggested that even if physical activity lead to more osteophytes it may be beneficial to the health of the joint as a whole.

Some of the conflicting results when studying risk factor for OA may be due to the use of different criteria for OA identification, and differences in study designs. The use of radiographic defined OA for case identification has its limitation since the correlation between radiographic findings and patients symptoms is not that good [37]. Joint replacement is a proxy for severe OA, and even though it will only identify a few of all those affected by the disease it will identify those were OA has severe implications, both for the affected individual, and due to severe economic impact on the society. The non-prospective studies have limitations due to recall bias, and also evidence of a tendency to over-report height and to under-report weight [38].

Information on how risk factors interact would be of great value. Two independent case-control studies have reported the combination of a high BMI and physically demanding work, particularly work involving knee bending, to be particularly damaging to the knee joint $[39,40]$.

With standardized measurements of height and weight, standardized questions on physical activity at both work, and at leisure we were able to investigate risk factors for severe $\mathrm{OA}$ in a large Norwegian cohort including both men and women, especially focusing on the interactions between these risk factors.

\section{Methods}

\section{Population}

Between 1985 and 1994 the National Health Screening Service (now part of the Norwegian Institute of Public Health) conducted population-based standardized cardiovascular health studies in all of Norway's 19 counties $[41,42]$. In addition The University of Troms $\varnothing$ carried out a similar study in the city of Tromsø (Tromsø III study) between 1986 and 1987 [43]. The median participation rate in these studies was $75 \%$ (range: 55 to $88 \%$ ). The purpose of all these studies was to investigate risk factors for cardiovascular disease.

By using the national 11-digit personal identification code we were able to link the data from the health screenings with the data on performed KR's from the Norwegian Arthroplasty Register. The Norwegian Arthroplasty Register was established by the Norwegian Orthopaedic Association, and started to include information on KR's from January 1994 [44]. The operating orthopaedic surgeon submits a standardised form to the register for each joint replacement performed. The form contains information about the diagnosis that led to the operation, the procedure, any previous $\mathrm{KR}$, or other operation performed in the joint, and the type of implant used. Data on death and emigration was collected from Statistics Norway.

The exposure variables were collected from the health screenings performed between 1985 and 1994. The start of follow up was set to January $1^{\text {st }}, 1994$, the date the Norwegian Arthroplasty Register started registration of KR's, and end of follow up was set to February $1^{\text {st }}, 2006$.

\section{Exclusion}

We did not include individuals younger than 16 years at the screening $(n=484)$, or older than 80 years at start of follow up $(n=50)$. Individuals who had information in the register about revision surgery, but no information on primary surgery $(\mathrm{n}=121)$, and individuals who according to 
Statistics Norway had died or emigrated before start of follow up $(n=4,076)$ were also excluded.

Of 320,226 individuals attending the health studies with complete information on the exposure variables, 315,495 (98.5\%) were eligible for the study; 20,484 from the Troms $\varnothing$ II study, and 295,011 from the cardiovascular screenings in the 19 Norwegian counties.

\section{Exposure variables}

The participants received a questionnaire with the invitation to the screening. They filled in the questionnaire at home and brought it to the screening where they had the opportunity to clarify misunderstandings with the study nurses. In all the screenings, body weight and height were measured at a consultation in a standardized way $[45,46]$. BMI was calculated as weight (in kilograms) divided by height (in meters) squared. Information on smoking habits was classified as; never smoker, former smoker, or current smoker. Information on physical activity at work and physical activity at leisure were each assessed in a four graded question classified as sedentary, moderate, intermediate or intensive (Table 1) [47]. The questions used to evaluate physical activity were first introduced in Sweden [47], and similar questions have been used by the World Health Organization in a study of trends and determinants in cardiovascular disease [48]. Both questions have been validated against maximum oxygen uptake during exercise [49]. The question concerning physical activity at leisure has been validated against maximum work capacity [43]. The question concerning physical activity at work has been validated against a 7days diary [50].

\begin{tabular}{|c|c|}
\hline \multicolumn{2}{|c|}{ Physical activity at work } \\
\hline Sedentary & $\begin{array}{l}\text { Predominantly sedentary, sitting (e.g. desk worker, watch } \\
\text { maker, sitting assembly line worker (light goods)) }\end{array}$ \\
\hline Moderate & $\begin{array}{l}\text { Sitting or standing, some walking (e.g. cashier, general } \\
\text { office worker, light tool and machinery worker, foreman) }\end{array}$ \\
\hline Intermediate & $\begin{array}{l}\text { Walking, some handling of material (e.g. mailman, waiter, } \\
\text { construction worker, heavy tool and machinery worker) }\end{array}$ \\
\hline Intensive & $\begin{array}{l}\text { Heavy manual labor (e.g. forestry worker, dock worker, } \\
\text { farm worker, ditch digger) }\end{array}$ \\
\hline \multicolumn{2}{|c|}{ Physical activity at leisure } \\
\hline Sedentary & Reading, watching television or other sedentary activities \\
\hline Moderate & $\begin{array}{l}\text { Walking, bicycling or moving around in other ways at } \\
\text { least } 4 \text { hours per week (including walking or cycling to } \\
\text { place of work, Sunday walks etc.) }\end{array}$ \\
\hline Intermediate & $\begin{array}{l}\text { Participation in recreational athletics, heavy garden work } \\
\text { etc. (note: duration of activity at least } 4 \text { hours a week) }\end{array}$ \\
\hline Intensive & $\begin{array}{l}\text { Participation in hard training or athletic competitions } \\
\text { regularly and several times a week }\end{array}$ \\
\hline
\end{tabular}

\section{Statistical analyses}

Cox proportional hazard regression method was used, calculating hazard ratios (hereafter called relative risks, (RR)) for having a KR. The event was defined as a participant's first knee replacement (any side) for the diagnosis of primary OA during follow-up, either a total knee joint replacement with or without a patella button, or a medial unicondylar knee replacement. Censoring occurred for KR performed for other diagnosis than primary osteoarthritis, for death, for emigration, and at end of follow up. Survival time was calculated as the number of years from start of follow up to the time of event or censoring. We included the continuous variable age, the variables BMI and height categorized into quartiles, the categorical variables smoking habits, physical activity at work, and physical activity at leisure. The analyses were also performed with BMI and weight as continuous variables.

We divided the cohort into sex specific quartiles according to BMI and height and performed the analyses comparing the three highest quartiles to the lowest one (the reference quartile). The cohort was also divided into three groups according to World Health Organizations definition of normal weight $\left(<25 \mathrm{~kg} / \mathrm{m}^{2}\right)$, overweight $\left(25 \mathrm{~kg} / \mathrm{m}^{2}-30 \mathrm{~kg} / \mathrm{m}^{2}\right)$, and obesity $\left(>30 \mathrm{~kg} / \mathrm{m}^{2}\right)$.

Population attributable risk (PAR) was calculated to estimate the possible reduction in KR's if those exposed to higher levels of BMI and physical activity at work were able to shift their level of BMI and work activity to a lower level [51].

Log minus log curves confirmed that the proportional hazard assumption for the Cox model was fulfilled (data not shown). The analyses were performed by SPSS version 19 (SPSS Inc., Chicago, IL).

The study was approved by The Norwegian Data Protection Authority, and the Regional Committee for Medical and Health Research Ethics South East.

The numbers of included individuals in the tables may vary slightly due to some missing values.

\section{Results}

153,795 men and 161,700 women were included in the study. The mean age for both sexes at screening was 43.0 years (SD 7.2), at start of follow up it was 46.8 years (SD 7.6), and at end follow up 58.8 years (SD 7.1). During 12 years of follow up, 1,323 individuals (0.42\%) received their first KR due to primary OA. Of these 225 were unicondylar and 1,098 were total knee replacements (Table 2).

367 participants were censored because they received a KR for conditions other than primary OA. The most frequent indications for surgery in these cases were rheumatoid arthritis $(\mathrm{n}=107)$ and sequela after meniscal injury $(n=81)$. A total of 19,690 individuals were censored because they died or emigrated during follow up. 
Table 2 Basic characteristics of the cohort of 315,495 Norwegian men and women

\begin{tabular}{lcc}
\hline & Men & Women \\
\hline No. of participants & 153,795 & 161,700 \\
No. of knee replacements for primary OA & 430 & 893 \\
BMl at screeening* & $25.4(3.2)$ & $24.3(4.0)$ \\
Age at screening years* & $43.1(7.2)$ & $43.0(7.3)$ \\
Age at start follow up years* & $46.8(7.6)$ & $46.7(7.6)$ \\
Age at operation* & $62.8(8.7)$ & $64.4(9.0)$ \\
Age at end follow up years* & $58.7(6.9)$ & $58.9(7.3)$ \\
\hline
\end{tabular}

*Mean (SD).
In the multivariate Cox regression analyses the risk of $K R$ increased with higher age at screening. The relative risk was 1.5 (95\% CI: 1.4-1.5) for both men and women per five years increase. Women had double risk (RR 2.7, 95\% CI: 2.3-3.3) compared to men for KR.

\section{Body mass index}

Men in the highest BMI quartile had more than six times the risk of KR compared to men in the lowest quartile of BMI (Table 3 and Figure 1).

For women the risk of KR was more than eleven times higher in the highest compared to the lowest BMI quartile (Table 4 and Figure 2).

Table 3 Crude rate and relative risk of KR due to primary OA in 153,795 Norwegian men

\begin{tabular}{|c|c|c|c|c|c|}
\hline & No. of participants & Person-years & $\begin{array}{l}\text { No. of knee } \\
\text { replacements }\end{array}$ & $\begin{array}{c}\text { KRs per } 10,000 \text { person-years } \\
\text { (crude rate) }\end{array}$ & $\begin{array}{l}\text { Multivariate adjusted } \\
\operatorname{RR}^{*}(95 \% \mathrm{Cl})\end{array}$ \\
\hline \multicolumn{6}{|c|}{ Body Mass Index, $\mathrm{kg} / \mathrm{m}^{2}$} \\
\hline$<23.3$ & 38,967 & 470,734 & 32 & 0.7 & 1 \\
\hline $23.4-25.1$ & 38,099 & 460,094 & 79 & 1.7 & $2.35(1.55-3.54)$ \\
\hline $25.2-27.2$ & 38,918 & 469,847 & 93 & 2.0 & $2.58(1.73-3.87)$ \\
\hline$>=27.3$ & 37,807 & 455,912 & 226 & 5.0 & $6.16(4.23-8.95)$ \\
\hline $\mathrm{P}$ (test for trend) & & & & & $<0.0001$ \\
\hline \multicolumn{6}{|c|}{ Physical activity at work } \\
\hline Sedentary & 58,430 & 705,549 & 114 & 1.6 & 1 \\
\hline Moderate & 43,757 & 528,129 & 132 & 2.5 & $1.51(1.18-1.95)$ \\
\hline Intermediate & 32,304 & 389,973 & 90 & 2.3 & $1.64(1.24-2.17)$ \\
\hline Intensive & 19,118 & 230,737 & 94 & 4.1 & $2.41(1.83-3.18)$ \\
\hline$P$ (test for trend) & & & & & $<0.0001$ \\
\hline \multicolumn{6}{|c|}{ Physical activity at leisure } \\
\hline Sedentary & 29,620 & 357,537 & 80 & 2.2 & 1 \\
\hline Moderate & 80,762 & 974,895 & 245 & 2.5 & $1.02(0.79-1.31)$ \\
\hline Intermediate & 38,982 & 470,681 & 98 & 2.1 & $0.96(0.71-1.30)$ \\
\hline Intensive & 4,350 & 52,544 & 6 & 1.1 & $0.84(0.36-1.94)$ \\
\hline P (test for trend) & & & & & 0.668 \\
\hline \multicolumn{6}{|l|}{ Height } \\
\hline$<174$ & 44,106 & 532,390 & 126 & 2.4 & 1 \\
\hline $175-178$ & 36,438 & 439,896 & 111 & 2.5 & $1.38(1.06-1.78)$ \\
\hline 179-182 & 35,289 & 426,040 & 91 & 2.1 & $1.33(1.01-1.76)$ \\
\hline$>=183$ & 37,960 & 458,286 & 102 & 2.2 & $1.64(1.25-2.15)$ \\
\hline P (test for trend) & & & & & 0.001 \\
\hline \multicolumn{6}{|l|}{ Smoking } \\
\hline Never smoker & 46,945 & 566,770 & 126 & 2.2 & 1 \\
\hline Former smoker & 41,371 & 499,259 & 161 & 3.2 & $1.00(0.79-1.27)$ \\
\hline Smoker & 65,479 & 790,606 & 143 & 1.8 & $0.82(0.64-1.04)$ \\
\hline$P$ (test for trend) & & & & & 0.092 \\
\hline
\end{tabular}

*Adjusted for age at screening, height, smoking habits, BMI and physical activity at work, and at leisure time. 


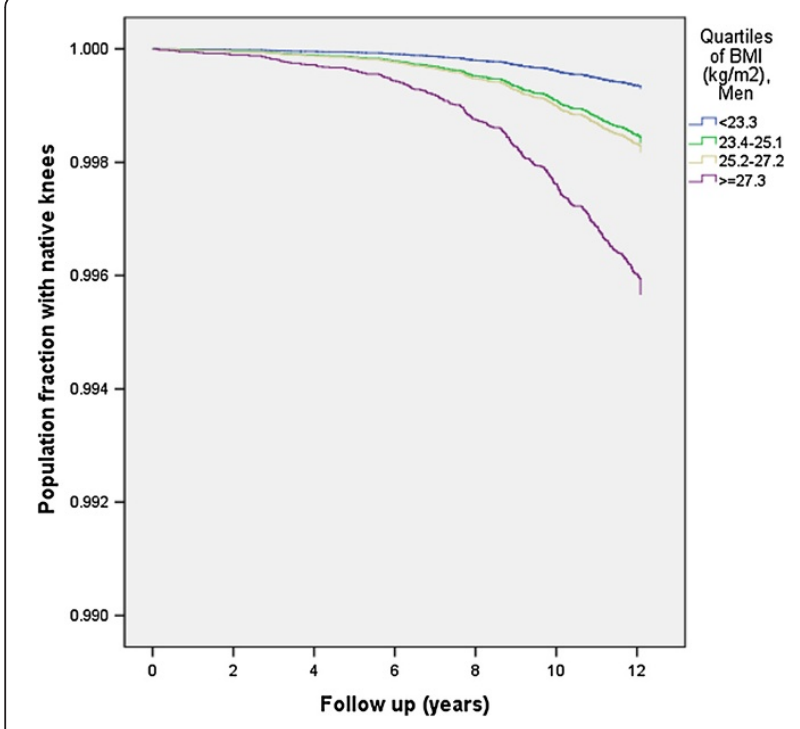

Figure 1 Survival curve by quartiles of BMI for 153,795 male native knees undergoing their first KR due to primary $O A$ in a Norwegian cohort. Adjusted for age at screening, smoking habits, height, physical activity at work and at leisure time.

The association between body weight $(\mathrm{kg})$ and $\mathrm{KR}$ was equally strong as that between BMI and KR (Additional file 1).

Dividing the cohort into groups according to the World health Organization's (WHO) definition of normal weight, overweight and obesity gave similar results. Men with a BMI over $30 \mathrm{~kg} / \mathrm{m}^{2}$ had a RR of 5.2 (95\% CI: 4.0-6.9) compared to men with a BMI below $25 \mathrm{~kg} / \mathrm{m}^{2}$. Women with a BMI over $30 \mathrm{~kg} / \mathrm{m}^{2}$ had a RR of 8.7 (95\% CI: 7.3-10.4) compared to women with a BMI below $25 \mathrm{~kg} / \mathrm{m}^{2}$.

When entering BMI and weight as continuous variables, the sex difference in the risk estimates disappeared. Both men and women had a relative risk of 1.3 per 5 kilos of weight (men; RR 1.29 (95\% CI: 1.25-1.34), women; RR 1.32 (95\% CI: 1.29-1.34)), and a relative risk of 1.2 per unit of BMI (men; RR 1.18 (95\% CI: 1.16-1.21), women; RR 1.16 (95\% CI: 1.15-1.17)).

\section{Physical activity}

Men had a dose-response relationship with increased risk for KR for all activity levels at work compared to sedentary activity (Table 3 ). Women with intermediate and intensive physical activity at work had an increased risk for KR compared to those with a sedentary activity level, whereas the risk in women with moderate physical activity was borderline significant (Table 4).

There were no associations between level of physical activity at leisure and the risk of later KR neither in men nor in women (Tables 3 and 4).

\section{Height}

In both men and women those in the tallest quartile had around 50\% increased risk for KR compared to those in the lowest quartile (Tables 3 and 4).

\section{Smoking}

We did not find any significant association between smoking and the risk of KR in men (Table 3). Compared to female never smokers, the risk of KR were 34\% lower in female smokers, and 19\% lower in female former smokers (Table 4).

The combined effect of physical activity at work and BMI We also analysed the combined effect of having a high BMI and a high level of activity at work (Table 5). For men in the highest quartile of BMI with intensive physical activity at work there was an 11 fold increase in the risk compared to men in the lowest quartile of BMI with a sedentary physical activity at work. For women the corresponding risk increase was about 16. We tested for possible interaction between high BMI and physical activity at work using an interaction term. The interaction term for BMI and physical activity at work did not reach significance $(\mathrm{p}=0.62)$.

Calculating PAR we found that if men with a BMI equal or above the third quartile and with moderate or higher levels of physical activity at work could reduce their risk to the levels of those unexposed (BMI lower than the third quartile and sedentary physical activity at work) we could expect to reduce the number of KR with up to $32 \%$. For women the corresponding percentage was $41 \%$.

\section{Discussion}

We have found strong dose-response associations between BMI and physical activity at work, and severely symptomatic $\mathrm{OA}$ of the knee. There was no association between physical activity at leisure and severe OA of the knee. Participants with both high BMI and strenuous work were at particularly high risk. The associations were apparent for both genders but women were at higher risk than men, and the risk increased with age.

\section{Strength and weaknesses}

Both BMI and occupational physical activity have been well documented as risk factors in previous literature. Our study confirms previous findings on these associations in a large unselected cohort of men and women, and brings new information on how overweight and physical activity at work interacts.

We used joint replacement with either unicondylar- or total knee prosthesis, as a marker of OA. Thus, we identified participants who developed severely symptomatic OA, who wanted a joint replacement, and who did not 
Table 4 Crude rate and relative risk of KR due to primary OA in 161,700 Norwegian women

\begin{tabular}{|c|c|c|c|c|c|}
\hline & $\begin{array}{c}\text { No. of } \\
\text { participants }\end{array}$ & Person-years & $\begin{array}{l}\text { No. of knee } \\
\text { replacements }\end{array}$ & $\begin{array}{l}\text { KRs per } 10,000 \text { person-years } \\
\text { (crude rate) }\end{array}$ & $\begin{array}{c}\text { Multivariate adjusted } \\
\mathrm{RR}^{*}(95 \% \mathrm{Cl}) \\
\end{array}$ \\
\hline \multicolumn{6}{|c|}{ Body Mass Index, $\mathrm{kg} / \mathrm{m}^{2}$} \\
\hline$<21.6$ & 40,526 & 489,541 & 35 & 0.7 & 1 \\
\hline $21.7-23.5$ & 39,562 & 477,775 & 73 & 1.5 & $1.93(1.29-2.89)$ \\
\hline $23.6-26.1$ & 40,691 & 491,052 & 177 & 3.6 & $3.92(2.72-5.64)$ \\
\hline$>=26.2$ & 40,911 & 491,705 & 608 & 12.4 & $11.06(7.83-15.62)$ \\
\hline$P$ (test for trend) & & & & & $<0.0001$ \\
\hline \multicolumn{6}{|c|}{ Physical activity at work } \\
\hline Sedentary & 46,050 & 555,499 & 201 & 3.6 & 1 \\
\hline Moderate & 84,368 & $1,017,358$ & 498 & 4.9 & $1.18(1.00-1.40)$ \\
\hline Intermediate & 27,744 & 334,751 & 149 & 4.5 & $1.30(1.05-1.61)$ \\
\hline Intensive & 3,343 & 40,230 & 45 & 11.2 & $2.29(1.65-3.18)$ \\
\hline$P$ (test for trend) & & & & & $<0.0001$ \\
\hline \multicolumn{6}{|c|}{ Physical activity at leisure } \\
\hline Sedentary & 31,322 & 377,346 & 190 & 5.0 & 1 \\
\hline Moderate & 113,127 & 113,127 & 624 & 55.2 & $0.99(0.84-1.16)$ \\
\hline Intermediate & 16,204 & 16,204 & 75 & 46.3 & $0.92(0.70-1.21)$ \\
\hline Intensive & 968 & 11,687 & 4 & 3.4 & $1.72(0.64-4.65)$ \\
\hline$P$ (test for trend) & & & & & 0.797 \\
\hline \multicolumn{6}{|l|}{ Height } \\
\hline$<161$ & 44,123 & 531,632 & 325 & 6.1 & 1 \\
\hline $162-165$ & 42,320 & 510,399 & 238 & 4.7 & $1.10(0.93-1.30)$ \\
\hline $166-169$ & 38,461 & 464,179 & 150 & 3.2 & $0.93(0.77-1.14)$ \\
\hline$>=170$ & 36,791 & 443,925 & 180 & 4.1 & $1.48(1.23-1.80)$ \\
\hline$P$ (test for trend) & & & & & 0.003 \\
\hline \multicolumn{6}{|l|}{ Smoking } \\
\hline Never smoker & 65,929 & 794,420 & 526 & 6.6 & 1 \\
\hline Former smoker & 31,174 & 376,055 & 163 & 4.3 & $0.81(0.68-0.96)$ \\
\hline Smoker & 64,597 & 779,720 & 204 & 2.6 & $0.66(0.56-0.78)$ \\
\hline$P$ (test for trend) & & & & & $<0.0001$ \\
\hline
\end{tabular}

*Adjusted for age at screening, height, smoking habits, BMI and physical activity at work, and at leisure time.

have contraindications to surgery. This may have introduced a bias, as severe obesity is a relative contraindication to surgery, leading us to underestimate the effect of obesity on the risk of needing a KR.

During the period of follow up data from the Norwegian Arthroplasty Register shows an increasing number of KR's performed in Norway; from 25.1 per 100,000 inhabitants in 1995 to 70.5 per 100,000 inhabitants in 2005 [52]. If one compares the age specific incidence rates of primary KR's between Norway and Sweden, two countries that are thought to have similar population and health care system, the rates differ. In the age group 55 to 64 the age specific incidence is 239 per 100,000 inhabitants in Norway, compared to 330 per 100,000 inhabitants in Sweden [53]. The increase in the number of performed KR's in
Norway, and the lower numbers of performed KR's in Norway compared to Sweden is probably explained by the fact that Sweden introduced KR as a routine procedure earlier than Norway.

Not every hospital in Norway performed the procedure in the early part of our follow up, and the indication for whom to operate may have changed as the procedure have become more common. It may be that the surgeons were more restrictive to operate on overweight and obese patients in the early part of follow up. This could lead to an underestimation of the association between overweight and KR.

The mean age at start of follow up was 47 years, and at end follow up 59 years. As the mean age at KR in Norway is 70 years there is a proportion of our cohort 


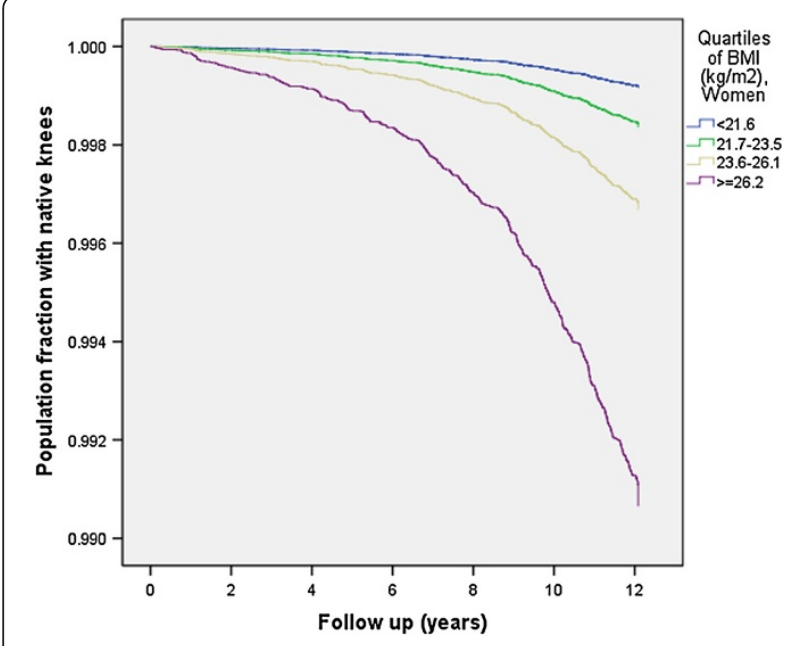

Figure 2 Survival curve by quartiles of BMI for 161,700 female native knees undergoing their first KR due to primary OA in a Norwegian cohort. Adjusted for age at screening, smoking habits, height, physical activity at work and at leisure time.

who will receive their KR after end of follow up [52]. This could be a bias since we know that persons with a high BMI tend to be younger when they receive their KR compared to persons of normal weight $[54,55]$. This could have led us to overestimate the effect of BMI on the total population. However, our results are comparable with previous studies making it unlikely that this bias account for a large part of our risk estimates. The possible effect on the other risk factors is less obvious.

The main strength of this study is that it involves a large unselected Norwegian cohort making the results generalizable. The mean age at screening was 43.0 years,

Table 5 Relative risks* for KR due to primary OA at different levels of BMI and physical activity at work

\begin{tabular}{lcccc}
\hline \multicolumn{5}{c}{ Physical activity at work } \\
\hline $\begin{array}{l}\text { Body mass } \\
\text { index, } \\
\text { kg/m }\end{array}$ & Sedentary & Moderate & Intermediate & Intensive \\
\hline Men & & & & \\
$<23.3$ & 1 & $1.2(0.5-2.9)$ & $1.2(0.4-3.3)$ & $1.9(0.7-5.3)$ \\
$23.4-25.1$ & $2.0(0.9-4.2)$ & $2.6(1.2-5.4)$ & $3.5(1.6-7.6)$ & $5.1(2.4-11.3)$ \\
$25.2-27.2$ & $1.2(0.5-2.8)$ & $4.1(2.1-8.3)$ & $3.7(1.7-7.8)$ & $5.6(2.7-12.0)$ \\
$>=27.3$ & $5.9(3.0-11.4))$ & $7.3(3.7-14.2)$ & $8.1(4.1-16.2)$ & $11.7(5.9-23.1)$ \\
Women & & & & \\
$<21.6$ & 1 & $0.6(0.3-1.3)$ & $0.8(0.3-2.3)$ & $3.1(0.7-13.8)$ \\
$21.7-23.5$ & $1.4(0.7-2.8)$ & $1.7(0.9-3.1)$ & $1.3(0.5-3.0)$ & $2.6(0.6-11.3)$ \\
$23.6-26.1$ & $2.8(1.5-5.2)$ & $3.2(1.8-5.6)$ & $3.1(1.6-6.0)$ & $7.9(3.5-17.7)$ \\
$>=26.2$ & $7.2(4.1-12.8)$ & $9.0(5.2-15.7)$ & $10.6(5.9-18.8)$ & $15.8(8.2-30.3)$ \\
\hline
\end{tabular}

${ }^{*}$ Adjusted for Age at screening, height, smoking habits, and physical activity at leisure $(95 \% \mathrm{Cl})$. an age were the incidence of knee OA is low [56], making it likely that the majority of the participants were without symptoms of $\mathrm{OA}$ at screening.

The health care system in Norway is publicly funded and thereby almost free of charge for the patients, and the majority of patients that are permanently or temporarily out of work are provided for by the public sick leave pension. Therefore we do not think that the participants' socioeconomic status represents a significant confounder neither with regards to inequality in the provision of surgery, nor due to differences in seeking surgery.

We do not have complete information on KR performed before the start of follow up, and some may erroneously have been classified as not operated. However, the mean age of the participants at start of follow up was 46.8, and this is an age were only a small proportion of the population will have undergone joint replacement. The completeness in the reporting of primary knee replacements to the Norwegian Arthroplasty Register is estimated to be $99 \%$, and the number of censorings that should have been events is probably small [57].

\section{Body mass index}

In our study group a higher BMI was associated with increased risk for joint replacement in the knee throughout the range of measured BMI, including the interval defined by WHO as normal. This concurs with the strong association between BMI and OA of the knee that has been identified in previous investigations [13,20,27,58-62]. Authors have used varying definitions of OA such as pain of certain duration, radiographic changes, or joint replacement surgery. Studies using joint replacement surgery as end point have reported risks comparable to the risks in our population [28,59-62]. As we had access to other important risk factors we could determine that BMI is a risk factor across gender, age, and level of physical activity, showing a dose-response relationship throughout the population's range of BMI.

Higher weight could be caused by inactivity resulting from pain in an osteoarthritic joint rather than extra weight leading to OA. In our investigation the mean time between the screening and the joint surgery was 17.2 years, and reverse causation is therefore unlikely. Other studies have similarly shown that obesity precedes the development of OA in the knee [27].

\section{Occupational activity}

We found a dose-response relationship between occupational activity and KR in both men and women. Occupational activities involving high physical workload, or special activities like kneeling, climbing and squatting have been shown to increase the risk of developing knee OA in several studies $[11,39,63,64]$. 
The combined effect of physical activity at work and BMI In our cohort persons with both a high BMI and intensive physical activity at work were at particularly increased risk for KR surgery. These results concur with the results from two previous case-control studies; In the study by Coggon et al. including persons at waiting list for $K R$ they found that those with a BMI $\geq 30 \mathrm{~kg} / \mathrm{m}^{2}$ and occupational activity with prolonged kneeling and squatting had an OR of 14.7 (95\% CI: 7.3-30.2) compared to those with a BMI $<25 \mathrm{~kg} /$ $\mathrm{m}^{2}$ and no occupational kneeling or squatting [39]. The study of Vrezas et al. of radiographic OA in 298 men also concluded with a multiplicative interaction mode for the combined effect of high BMI and kneeling/squatting at work [40]. In a prospective cohort study of symptomatic knee OA Martin et al. also found evidence for a multiplicative interaction between BMI and heavy lifting and the association with clinical OA [8].

We did not find evidence for an interaction between BMI and physical activity at work, and the effect of BMI is therefor the same for all levels of physical activity at work. These results strongly indicate that individuals with heavy labour should be advised to maintain a body weight within the normal range.

To estimate the possible benefit of prevention regarding the combined effect of BMI and physical activity at work we calculated the PAR percentage. If men and women with a BMI equal or above the third quartile and with moderate or higher levels of physical activity at work could reduce their risk to the levels of those unexposed (BMI lower than the third quartile and sedentary physical activity at work) we found that there is a potential for a reduction in the numbers of KR's with $32 \%$ for men and $42 \%$ for women.

The screening question about work activity was not designed to evaluate knee problems. We were not able to explore which specific activity that was harmful to the knee joint. The participants were asked about their activity at work throughout the last 12 months leading up to the screening, and we had no further information on the duration of the activity level.

Using $\mathrm{KR}$ as end-point, we assume that participants undergo joint replacement surgery when the disease becomes severely symptomatic. This may indicate that the joint has reached a certain stage of pathology, but the time of surgery may also be influenced by the participants need for maintaining physical activity. Having a physically demanding job may force a person to apply for knee replacement surgery at a more moderate stage of joint pathology. In Norway the economic incentive for keeping on working after symptom onset is less than in some other countries, due to a generous public pension for the sick and disabled as mentioned above. Detailed information on life-time exposure to physical activity might further elucidate the matter: if strenuous physical activity early in life shows a stronger association with later knee replacement it would indicate that the level of joint pathology is the key factor triggering surgery. If physical activity later in life is more closely associated with KR it might indicate that the person's need for maintaining physical activity after the onset of OA strongly influences the decision to undergo surgery.

\section{Physical activity at leisure}

We did not find any effect of spending a lot of leisure time doing physical activity on later risk of KR. Other studies have had conflicting results. Some have found a relationship, but varying according with the type of physical activity. There seems to be an association with repetitive high impact sports like soccer, team handball and ice hockey, and the risk is strongly associated with previous joint injury $[6,65,66]$. Also studies of other intensive activities but without high impact on the joint like long distance skiing have shown an increased risk of knee OA [67]. In studies of normal exercise like jogging, gymnastics and swimming, the association appears less important $[13,36,58,68]$. Our results are comparable to the findings in a resent Swedish cohort study that found no association between physical activity at leisure and KR [13]. A large prospective cohort study that also investigated severe OA requiring $\mathrm{KR}$ reported a dose response relationship between increasing levels of physical activity at leisure and KR. Although the effect was statistically significant, it was clinically small [14]. This study has many similarities with our current study. The reason for the discrepancies in the results may be related to joint injury. We did not have information on previous trauma, but we censored those who received an arthroplasty secondary to previous meniscal, or ligamentous injury. The effect of physical activity at leisure may appear more prominent if one investigates those receiving an arthroplasty due to secondary OA. The study by Wang et al. did not adjust for trauma, and since this is a well documented risk factor it may have affected the results.

The screening questions about physical activity at leisure used in our study were designed to evaluate the effect on cardiovascular disease, and they did not collect information regarding the level of impact on the joint. It might be that the classification of activity was not sensitive enough to evaluate the effect of particular kinds of physical activity on later OA. In our cohort only $2.6 \%$ of the men and $0.5 \%$ of the women reported intensive physical activity at leisure (hard training or athletic competitions regularly and several times a week). These small numbers in the most active category may also be a reason that we do not find an effect. However our findings suggest that physical activity at leisure as performed by the major part of the Norwegian population does not increase the risk for later severe knee OA. 


\section{Smoking}

Female smokers had a lower risk of KR compared to never-smokers. However, since we use surgery with $K R$ as an endpoint, and it may be that smokers had comorbidities that made them unfit for surgery leading to a falsely low number of KR's in the smoking group caution should be made when interpreting these results.

\section{Height}

Men and women in the tallest quartiles had an increased risk for later KR due to primary OA. Previous studies have similarly found an increased risk for OA of the hip among tall men and women [69]. A prospective cohort study of women reported an increased risk for KR in tall women [59]. The association may be explained by mechanical factors such as a longer weight arm for muscles working across the knee joint, rendering the joint more susceptible to wear and tear. Another possibility as proposed by Liu et al. is that nutritional factors in early life both affect adult height as well as bone development and mineralization and leads to a predisposition for $\mathrm{OA}$ in tall individuals.

\section{Conclusions}

Our findings confirm previous reports on a strong doseresponse relationship between $\mathrm{BMI}$ and $\mathrm{KR}$ due to primary OA. A higher BMI entailed increased risk for severely symptomatic OA of the knee also within the range of BMI defined as normal. A higher level of physical activity at work increased the risk for KR later in life. The combination of heavy labor and a high BMI was particularly hazardous to the knee joint, leading to a 12-fold increase in risk for knee replacement among men, and a 16-fold increase among women

Preventive measures should be directed at weight loss and work ergonomics, and be particularly aimed at doubly exposed persons.

\section{Additional file}

Additional file 1: Relative risk of KR due to primary OA according to quartile of weight.

\section{Competing interests}

The authors declare that they have no competing interests.

\section{Authors' contributions}

HA participated in the conception and design of the study, performed the analysis and the interpretation of the data, and drafted the manuscript. LN obtained funding. LN, HEM, GBF, OF were involved in the conception and design of the study. GBF and HM performed analysis and interpretation of the data. VB contributed with statistical expertise. All the authors revised the manuscript for important intellectual content, and read and approved the final version of the manuscript.

\section{Funding sources}

The work is partly supported by grants from Helse Sør-Øst, The Norwegian Orthopedic Association and from Dr. Trygve Gythfeldt og frues forskningsfond. These sponsors have no involvement in any parts of the study itself.

\section{Author details}

${ }^{1}$ Orthopaedic department, Telemark Hospital, Skien, Norway. ${ }^{2}$ Section for Preventive Medicine and Epidemiology, University of Oslo, Oslo, Norway. ${ }^{3}$ Norwegian Institute of Public Health, Division of Epidemiolgy, Oslo, Norway. ${ }^{4}$ Orthopaedic department, Oslo University Hospital, Oslo, Norway. ${ }^{5}$ Faculty of medicine, University of Oslo, Oslo, Norway. ${ }^{6}$ The Norwegian Arthroplasty Register, Department of Orthopaedic Surgery, Haukeland University Hospital, Bergen, Norway. ${ }^{7}$ Department of Orthopaedic Surgery, Haukeland University Hospital, Bergen, Norway. ${ }^{8}$ Department of Surgical Sciences, Faculty of

Medicine and Dentistry, Bergen, Norway.

Received: 3 September 2013 Accepted: 10 June 2014

Published: 23 June 2014

\section{References}

1. Spector TD, Cicuttini F, Baker J, Loughlin J, Hart D: Genetic influences on osteoarthritis in women: a twin study. BMJ 1996, 312:940-943.

2. Leyland KM, Hart DJ, Javaid MK, Judge A, Kiran A, Soni A, Goulston LM, Cooper C, Spector TD, Arden NK: The natural history of radiographic knee osteoarthritis: a fourteen-year population-based cohort study. Arthritis Rheum 2012, 64:2243-2251.

3. Li Y, Wei $X$, Zhou J, Wei L: The age-related changes in cartilage and osteoarthritis. [Review]. BioMed Res Int 2013, article ID 916530. http://dx.doi.org/10.1155/2013/916530.

4. Felson DT, Nevitt MC, Zhang Y, Aliabadi P, Baumer B, Gale D, Li W, Yu W, $\mathrm{Xu}$ L: High prevalence of lateral knee osteoarthritis in Beijing Chinese compared with Framingham Caucasian subjects. Arthritis Rheum 2002, 46:1217-1222

5. Srikanth VK, Fryer JL, Zhai G, Winzenberg TM, Hosmer D, Jones G: A meta-analysis of sex differences prevalence, incidence and severity of osteoarthritis. Osteoarthritis Cartilage 2005, 13(9):769-781.

6. Toivanen AT, Heliovaara M, Impivaara O, Arokoski JP, Knekt P, Lauren H, Kroger $\mathrm{H}$ : Obesity, physically demanding work and traumatic knee injury are major risk factors for knee osteoarthritis-a population-based study with a follow-up of 22 years. Rheumatology (Oxford) 2010, 49:308-314.

7. Muthuri SG, McWilliams DF, Doherty M, Zhang W: History of knee injuries and knee osteoarthritis: a meta-analysis of observational studies. [Review]. Osteoarthritis Cartilage 2011, 19(11):1286-1293.

8. Martin KR, Kuh D, Harris TB, Guralnik JM, Coggon D, Wills AK: Body mass index, occupational activity, and leisure-time physical activity: an exploration of risk factors and modifiers for knee osteoarthritis in the 1946 British birth cohort. BMC Musculoskelet Disord 2013, 14:219.

9. Vingard E, Alfredsson L, Goldie I, Hogstedt C: Occupation and osteoarthrosis of the hip and knee: a register-based cohort study. Int J Epidemiol 1991, 20:1025-1031.

10. Felson DT, Hannan MT, Naimark A, Berkeley J, Gordon G, Wilson PW Anderson J: Occupational physical demands, knee bending, and knee osteoarthritis: results from the Framingham Study. J Rheumatol 1991, 18:1587-1592

11. Jarvholm B, From C, Lewold S, Malchau H, Vingard E: Incidence of surgically treated osteoarthritis in the hip and knee in male construction workers. Occup Environ Med 2008, 65:275-278.

12. Spector TD, Harris PA, Hart DJ, Cicuttini FM, Nandra D, Etherington J, Wolman RL, Doyle DV: Risk of osteoarthritis associated with long-term weight-bearing sports: a radiologic survey of the hips and knees in female ex-athletes and population controls. Arthritis Rheum 1996, 39(6):988-995.

13. Ageberg $E$, Engstrom $G$, de Verdier Gerhardsson M, Rollof J, Roos E, Lohmander L: Effect of leisure time physical activity on severe knee or hip osteoarthritis leading to total joint replacement: a population-based prospective cohort study. BMC Musculoskelet Disord 2012, 13:73.

14. Wang Y, Simpson JA, Wluka AE, Teichtahl AJ, English DR, Giles GG, Graves S, Cicuttini FM: Is physical activity a risk factor for primary knee or hip replacement due to osteoarthritis? A prospective cohort study. J Rheumatol 2011, 38:350-357. 
15. Racunica TL, Teichtahl AJ, Wang Y, Wluka AE, English DR, Giles GG, O'Sullivan R, Cicuttini FM: Effect of physical activity on articular knee joint structures in community-based adults. Arthritis Rheum 2007, 57(7):1261-1268.

16. Vignon E, Valat JP, Rossignol M, Avouac B, Rozenberg S, Thoumie P, Avouac J, Nordin M, Hilliquin P: Osteoarthritis of the knee and hip and activity: a systematic international review and synthesis (OASIS). [Review] [103 refs]. Joint Bone Spine 2006, 73(4):442-455.

17. Mork PJ, Holtermann A, Nilsen TI: Effect of body mass index and physica exercise on risk of knee and hip osteoarthritis: longitudinal data from the Norwegian HUNT Study. J Epidemiol Community Health 2012, 66:678-683

18. Brouwer GM, van Tol AW, Bergink AP, Belo JN, Bernsen RM, Reijman M, Pols HA, Bierma-Zeinstra SM: Association between valgus and varus alignment and the development and progression of radiographic osteoarthritis of the knee. Arthritis Rheum 2007, 56:1204-1211.

19. Felson DT, Niu J, Gross KD, Englund M, Sharma L, Cooke TD, Guermazi A Roemer FW, Segal N, Goggins JM, Lewis CE, Eaton C, Nevitt MC: Valgus malalignment is a risk factor for lateral knee osteoarthritis incidence and progression: findings from the Multicenter Osteoarthritis Study and the Osteoarthritis Initiative. Arthritis Rheum 2013, 65(2):355-362.

20. Felson DT, Zhang Y, Hannan MT, Naimark A, Weissman B, Aliabadi P, Levy D: Risk factors for incident radiographic knee osteoarthritis in the elderly: the Framingham Study. Arthritis Rheum 1997, 40:728-733.

21. Mnatzaganian G, Ryan P, Reid CM, Davidson DC, Hiller JE: Smoking and primary total hip or knee replacement due to osteoarthritis in 54,288 elderly men and women. BMC Musculoskelet Disord 2013, 14:262.

22. Wilder FV, Hall BJ, Barrett JP: Smoking and osteoarthritis: is there an association? The Clearwater Osteoarthritis Study. Osteoarthritis Cartilage 2013, 11(1):29-35.

23. Hart DJ, Spector TD: Cigarette smoking and risk of osteoarthritis in women in the general population: the Chingford study. Ann Rheum Dis 1993, 52(2):93-96.

24. Hui M, Doherty M, Zhang W: Does smoking protect against osteoarthritis? Meta-analysis of observational studies. [Review]. Ann Rheum Dis 2011, 70(7):1231-1237

25. Blagojevic M, Jinks C, Jeffery A, Jordan KP: Risk factors for onset of osteoarthritis of the knee in older adults: a systematic review and meta-analysis. [Review] [101 refs]. Osteoarthritis Cartilage 2010, 18:24-33.

26. Pearce F, Hui M, Ding C, Doherty M, Zhang W: Does smoking reduce the progression of osteoarthritis? Meta-analysis of observational studies. Arthritis Care Res 2013, 65(7):1026-1033.

27. Felson DT, Anderson JJ, Naimark A, Walker AM, Meenan RF: Obesity and knee osteoarthritis. The Framingham Study. Ann Intern Med 1988, 109:18-24.

28. Lohmander LS, de Verdier Gerhardsson M, Rollof J, Nilsson PM, Engstr+Âm G: Incidence of severe knee and hip osteoarthritis in relation to different measures of body mass: a population-based prospective cohort study. Ann Rheum Dis 2009, 68:490-496.

29. Hart DJ, Doyle DV, Spector TD: Incidence and risk factors for radiographic knee osteoarthritis in middle-aged women: the Chingford Study. Arthritis Rheum 1999, 42:17-24.

30. Jarvholm B, Lewold S, Malchau H, Vingard E: Age, bodyweight, smoking habits and the risk of severe osteoarthritis in the hip and knee in men. Eur J Epidemiol 2005, 20:537-542.

31. Holmberg S, Thelin A, Thelin N: Knee osteoarthritis and body mass index: a population-based case-control study. Scand J Rheumato/ 2005, 34:59-64.

32. Mnatzaganian G, Ryan P, Norman PE, Davidson DC, Hiller JE: Smoking, body weight, physical exercise, and risk of lower limb total joint replacement in a population-based cohort of men. Arthritis Rheum 2011, 63:2523-2530.

33. McWilliams DF, Leeb BF, Muthuri SG, Doherty M, Zhang W: Occupational risk factors for osteoarthritis of the knee: a meta-analysis. [Review]. Osteoarthritis Cartilage 2011, 19:829-839.

34. Jensen LK: Knee osteoarthritis: influence of work involving heavy lifting, kneeling, climbing stairs or ladders, or kneeling/squatting combined with heavy lifting. [Review] [45 refs]. Occup Environ Med 2008, 65(2):72-89.

35. Hannan MT, Felson DT, Anderson JJ, Naimark A: Habitual physical activity is not associated with knee osteoarthritis: the Framingham Study. J Rheumatol 1993, 20(4):704-709.

36. Felson DT, Niu J, Clancy M, Sack B, Aliabadi P, Zhang Y: Effect of recreational physical activities on the development of knee osteoarthritis in older adults of different weights: the Framingham Study. Arthritis Rheum 2007, 57:6-12.
37. Hannan MT, Felson DT, Pincus T: Analysis of the discordance between radiographic changes and knee pain in osteoarthritis of the knee. J Rheumatol 1994, 27(6):1513-1517.

38. Nawaz H, Chan W, Abdulrahman M, Larson D, Katz DL: Self-reported weight and height: implications for obesity research. Am J Prev Med 2001, 20(4):294-298.

39. Coggon D, Croft P, Kellingray S, Barrett D, McLaren M, Cooper C: Occupational physical activities and osteoarthritis of the knee. Arthritis Rheum 2000, 43:1443-1449.

40. Vrezas I, Elsner G, Bolm-Audorff U, Abolmaali N, Seidler A: Case-control study of knee osteoarthritis and lifestyle factors considering their interaction with physical workload. Int Arch Occup Environ Health 2010, 83:291-300

41. Tverdal A, Bjartveit K: Health consequences of reduced daily cigarette consumption. Tob Control 2006, 15:472-480.

42. Tverdal A, Hjellvik V, Selmer R: Heart rate and mortality from cardiovascular causes: a 12 year follow-up study of 379,843 men and women aged 40-45 years. Eur Heart J 2008, 29:2772-2781.

43. Lochen ML, Rasmussen K: The Tromso study: physical fitness, self reported physical activity, and their relationship to other coronary risk factors. J Epidemiol Community Health 1992, 46:103-107.

44. Furnes O, Espehaug B, Lie SA, Vollset SE, Engesaeter LB, Havelin LI: Early failures among 7,174 primary total knee replacements: a follow-up study from the Norwegian Arthroplasty Register 1994-2000. Acta Orthop Scand 2002, 73:117-129.

45. Tverdal A, Stensvold I, Solvoll K, Foss OP, Lund-Larsen P, Bjartveit K: Coffee consumption and death from coronary heart disease in middle aged Norwegian men and women. BMJ 1990, 300:566-569.

46. Thelle DS, Foorde OH, Try K, Lehmann EH: The Tromsoo heart study. Methods and main results of the cross-sectional study. Acta Med Scand 1976, 200:107-118

47. Saltin B, Grimby G: Physiological analysis of middle-aged and old former athletes. Comparison with still active athletes of the same ages. Circulation 1968, 38:1104-1115.

48. Stender M, Hense HW, Doring A, Keil U: Physical activity at work and cardiovascular disease risk: results from the MONICA Augsburg study. Int J Epidemiol 1993, 22:644-650.

49. Wilhelmsen L, Tibblin G, Aurell M, Bjure J, Ekstrom-Jodal B, Grimby G Physical activity, physical fitness and risk of myocardial infarction. Adv Cardiol 1976, 18:217-230.

50. Stender M, Doring A, Hense HW, Schlichtherle S, M'Harzi S, Keil U: Comparison of 2 methods for the assessment of physical activity]. [German]. Soz Praventivmed 1991, 36:176-183.

51. Levin ML: The occurrence of lung cancer in man. Acta Unio Internationalis Contra Cancrum 1953, 9(3):531-541.

52. The Norwegian Arthroplasty Register Report 2013: 2013. http://nrlweb.ihelse.net

53. Robertsson O, Bizjajeva S, Fenstad AM, Furnes O, Lidgren L, Mehnert F Odgaard A, Pedersen AB, Havelin LI: Knee arthroplasty in Denmark, Norway and Sweden. Acta Orthop 2010, 81:82-89.

54. Changulani M, Kalairajah Y, Peel T, Field RE: The relationship between obesity and the age at which hip and knee replacement is undertaken. J Bone Joint Surg (Br) 2008, 90-B:360-363.

55. Gandhi R, Wasserstein D, Razak F, Davey JR, Mahomed NN: BM independently predicts younger age at hip and knee replacement. Obesity (Silver Spring) 2010, 18:2362-2366.

56. Oliveria SA, Felson DT, Reed Jl, Cirillo PA, Walker AM: Incidence of symptomatic hand, hip, and knee osteoarthritis among patients in a health maintenance organization. Arthritis Rheum 1995, 38:1134-1141.

57. Espehaug B, Furnes O, Havelin LI, Engesæter LB, Vollset SE, Kindseth O: Registration completeness in the Norwegian Arthroplasty Register. Acta Orthop 2006, 77:49-56.

58. Cooper C, Snow S, McAlindon TE, Kellingray S, Stuart B, Coggon D, Dieppe PA: Risk factors for the incidence and progression of radiographic knee osteoarthritis. Arthritis Rheum 2000, 43:995-1000.

59. Liu B, Balkwill A, Banks E, Cooper C, Green J, Beral V, on behalf of the Million Women Study Collaborators: Relationship of height, weight and body mass index to the risk of hip and knee replacements in middle-aged women. Rheumatology (Oxford) 2007, 46:861-867.

60. Bourne R, Mukhi S, Zhu N, Keresteci M, Marin M: Role of obesity on the risk for total hip or knee arthroplasty. Clin Orthop Relat Res 2007, 465:185-188 
61. Wendelboe AM, Hegmann KT, Biggs JJ, Cox CM, Portmann AJ, Gildea JH, Gren LH, Lyon JL: Relationships between body mass indices and surgical replacements of knee and hip joints. Am J Prev Med 2003, 25:290-295.

62. Coggon D, Reading I, Croft P, McLaren M, Barrett D, Cooper C: Knee osteoarthritis and obesity. Int J Obes Relat Metab Disord 2001, 25:622-627.

63. Cooper C, McAlindon T, Coggon D, Egger P, Dieppe P: Occupational activity and osteoarthritis of the knee. Ann Rheum Dis 1994, 53:90-93.

64. Allen KD, Chen JC, Callahan LF, Golightly YM, Helmick CG, Renner JB, Jordan JM: Associations of occupational tasks with knee and hip osteoarthritis: the Johnston County Osteoarthritis Project. J Rheumatol 2010, 37:842-850.

65. Gelber AC, Hochberg MC, Mead LA, Wang NY, Wigley FM, Klag MJ: Joint injury in young adults and risk for subsequent knee and hip osteoarthritis. Ann Intern Med 2000, 133:321-328.

66. Tveit M, Rosengren BE, Nilsson JA, Karlsson MK: Former male elite athletes have a higher prevalence of osteoarthritis and arthroplasty in the hip and knee than expected. Am J Sports Med 2012, 40:527-533.

67. Michaelsson K, Byberg L, Ahlbom A, Melhus H, Farahmand BY: Risk of severe knee and hip osteoarthritis in relation to level of physical exercise: a prospective cohort study of long-distance skiers in Sweden. PLoS ONE [Electronic Resource] 2011, 6(3):e18339.

68. Eastmond CJ, Hudson A, Wright V: A radiological survey of the hips and knees in female specialist teachers of physical education. Scand J Rheumatol 1979, 8:264-268.

69. Flugsrud GB, Nordsletten L, Espehaug B, Havelin LI, Engeland A, Meyer HE: The impact of body mass index on later total hip arthroplasty for primary osteoarthritis. Arthritis Rheum 2006, 54:802-807.

\section{Submit your next manuscript to BioMed Central and take full advantage of:}

- Convenient online submission

- Thorough peer review

- No space constraints or color figure charges

- Immediate publication on acceptance

- Inclusion in PubMed, CAS, Scopus and Google Scholar

- Research which is freely available for redistribution 